\title{
Response to Krishnasamy et al
}

\author{
William Morello $^{1} \cdot$ Federica Alessandra Vianello $^{1} \cdot$ Emanuele Proverbio $^{1} \cdot$ Giovanni Montini $^{1}[$
}

Received: 3 December 2021 / Revised: 3 December 2021 / Accepted: 3 December 2021 / Published online: 10 January 2022

(c) The Author(s), under exclusive licence to International Pediatric Nephrology Association 2022

\section{Dear Editors,}

We thank Dr. Krishnasamy and co-authors for their letter highlighting their experience with COVID-19 in India [1] in response to our review and recommendations on the management of idiopathic nephrotic syndrome (INS) during the pandemic [2]. As the authors stated, this publication only became available after our systematic search of the literature was performed and therefore it was not included in the review.

In their paper [1], which reported retrospectively collected data from 4 pediatric nephrology centers in New Delhi, the authors describe a mortality rate of $4.5 \%$ in children with INS and SARS-CoV-2 infection (2/44), and they identify a concomitant relapse as a predictor of a worse outcome. Their findings are very different from the data summarized in our review [2] and the results of a new search performed on 30 November 2021, including the first collaborative European report and a national study performed by the Italian Society of Paediatric Nephrology.

There is only 1 other collaborative study reporting a similar mortality rate $(3.5 \%)$ in paediatric patients affected by kidney diseases and SARS-CoV-2 infection [3], but the underlying clinical condition of the fatal cases is not specified (INS vs. other kidney diseases). Interestingly, all deaths were in developing countries, with 3 out of 4 in India.

The unexpected dismal outcome of INS patients reported by Krishnasamy et al. may be related to a distinct genetic background, which is believed to influence the course of SARS-CoV-2 infection, or a different approach to INS relapses and COVID-19 themselves. Therefore, it will be crucial to understand if similar complications will be reported in the near future by others, and how this mortality rate compares to that expected for children with SARSCoV-2 infection or those with INS relapses in India.

However, according to the available literature, it is still correct to affirm that the course of SARS-CoV-2 infection is mostly mild in children with INS, even during relapses.

SARS-CoV-2 infection may be complicated by acute kidney injury or tubular damage, in children with and without underlying kidney conditions. Indeed, our recommendations suggest monitoring SARS-CoV-2 infection for signs of relapse in children with INS and support SARS-CoV-2 vaccination in this population. Moreover, we recommend considering hospital admission in the case of clinical worsening [2].

On this basis, we believe our recommendations are still effective and helpful for the management of children with INS during the pandemic.

\section{References}

1. Krishnasamy S, Mantan M, Mishra K, Kapoor K et al (2021) SARS-CoV-2 infection in children with chronic kidney disease. Pediatr Nephrol. https://doi.org/10.1007/S00467-021-05218-1

2. Morello W, Vianello FA, Proverbio E, Peruzzi L et al (2021) COVID-19 and idiopathic nephrotic syndrome in children: systematic review of the literature and recommendations from a highly affected area. Pediatr Nephrol. https://doi.org/10.1007/ S00467-021-05330-2

3. Marlais M, Wlodkowski T, Al-Akash S, Ananin P et al (2020) COVID-19 in children treated with immunosuppressive medication for kidney diseases. Arch Dis Child 106:798-801. https://doi. org/10.1136/archdischild-2020-320616

Publisher's note Springer Nature remains neutral with regard to jurisdictional claims in published maps and institutional affiliations.

Giovanni Montini

giovanni.montini@unimi.it

1 Pediatric Nephrology, Dialysis and Transplant Unit, Fondazione IRCCS Ca' Granda, Ospedale Maggiore Policlinico Di Milano, via Commenda 9, 20122 Milano, Italy 